\title{
Анализ современной практики формирования готовности \\ к инновационной деятельности будущих специалистов сферы государственного управления
}

\author{
Провоторова Н.В. \\ Луганский государственный педагогический университет, \\ ЛНР, 91011, г. Луганск, ул. Оборонная, 2 \\ E-mail: provotorova.natalija@yandex.ru
}

\begin{abstract}
Аннотация. Одной из проблем системы государственного управления является не соответствующий современным требованиям профессиональный уровень государственных гражданских служащих. Несмотря на многочисленность публикаций по теме подготовки госслужащих, качественные показатели готовности к инновационной деятельности остаются недостаточно изучены. Целью данного исследования является выявление особенностей современной практики формирования готовности к инновационной деятельности будущих специалистов сферы государственного управления и определение критериального аппарата для создания модели формирования готовности будущих специалистов сферы государственного управления. В результате исследования выделены критерии, показатели и уровни готовности к инновационной деятельности будущих специалистов сферы государственного управления. Сделаны выводы о несовершенстве современной практики подготовки госслужащих и перечислены его причины, в том числе отмечено несоответствие норм и стандартов регламентирующих документов. Полученные результаты свидетельствуют о необходимости создания модели готовности будущих специалистов сферы государственного управления, которая значительно повысит эффективность их профессиональной подготовки.
\end{abstract}

Ключевые слова: профессиональная подготовка, инновационная деятельность, нормативная база подготовки госслужащих, квалификационные требования к госслужащим, ключевые компетенции, критерии готовности к инновационной деятельности, показатели готовности к инновационной деятельности, уровни готовности к инновационной деятельности.

Для цитирования: Провоторова Н.В., 2021. Анализ современной практики формирования готовности к инновационной деятельности будущих специалистов сферы государственного управления. Вопросы журналистики, педагогики и языкознания, 40 (3): 347-357. DOI: $10.52575 / 2712-7451-2021-40-3-347-357$

\section{Analysis of Modern Practice of Formation of Readiness for Innovative Activity of Future Specialists in the Field of Public Administration}

\author{
Nataliia V. Provotorova \\ Lugansk State Pedagogical University, \\ 2 Oboronnaya St, Lugansk, 910011, LNR, \\ E-mail: provotorova.natalija@yandex.ru
}

Annotation. One of the problems of the public administration system is the professional level of state civil servants that does not meet modern requirements. Despite the numerous publications on the topic of training civil servants, qualitative indicators of readiness for innovation activity remain insufficiently 
studied. The purpose of this study is to identify the features of the modern practice of forming the readiness for innovative activity of future specialists in the field of public administration and to determine the criteria for creating a model of forming the readiness of future specialists in the field of public administration. In the course of the research, the author's definitions of the concepts innovative activity of a future specialist in the field of public administration and professional readiness for innovative activity of future specialists in the field of public administration are formulated. The analysis of normative documents regulating the training of state civil servants in the higher education system is carried out. As a result of the study, the criteria, indicators and levels of readiness for innovative activity of future specialists in the field of public administration are identified. Conclusions are drawn about the imperfection of the modern practice of training civil servants and its causes are listed, including the discrepancy between the norms and standards of regulatory documents. The results obtained indicate the need to create a model of readiness of future specialists in the field of public administration, which will significantly increase the effectiveness of their professional training.

Keywords: professional training, innovation activity, regulatory framework for training civil servants, qualification requirements for civil servants, key competencies, criteria for readiness for innovation activity, indicators of readiness for innovation activity, levels of readiness for innovation activity

For citation: Provotorova N.V., 2021. Analysis of Modern Practice of Formation of Readiness for Innovative Activity of Future Specialists in the Field of Public Administration. Issues in Journalism, Education, Linguistics, 40 (3): 347-357 (in Russian). DOI: 10.52575/2712-7451-2021-40-3-347-357

\section{Введение}

Динамично развивающийся социум накладывает свой отпечаток на систему государственного управления. В настоящее время в бурном потоке информационных процессов и административных преобразований современная система государственного управления испытывает проблемы кадрового обеспечения: недостаточно специалистов, способных плодотворно работать в современных условиях [Карелина, 2009; Марченко, Марченко, 2010; Мустафина, Богатырёва, 2014]. Это связано с профессиональной подготовкой в высших учебных заведениях, которая должна осуществляться с учетом проводимых общественных реформ и внедрением инновационных форм управления. Важнейшим условием эффективной подготовки будущих специалистов сферы государственного управления является формирование у них готовности к инновационной деятельности.

Проблемам готовности к инновационной деятельности специалистов сферы государственного управления уделяется большое внимание в научных трудах. Ученые исследуют различные аспекты готовности, в частности:

- факторы формирования инновационной деятельности субъектов государственного управления [Никитина, 2013];

- мотивационно-ценностное отношение к профессиональной деятельности, владение инструментами достижения поставленных задач, способность их творческой реализации [Чурсина, 2014];

- совокупности потребностей, установок, интересов, целей, склонностей, идеалов и убеждений [Долгова, 2013];

- соответствующие профессиональные компетенции [Акимов, Загороднюк, 2013];

- уровень аналитического мышления [Кузьменко, 2014];

- уровень инновационной культуры [Коновалова, 2013];

- уровень развития необходимых качеств [Коновалова, 2013; Чепляев, 2016; Атнашев, 2017] и прочее.

Несмотря на активное изучение вопроса готовности к инновационной деятельности будущих специалистов сферы государственного управления, критерии, показатели и уровни профессиональной готовности с учетом требований основных документов, состав- 
ляющих нормативную базу, на сегодняшний день четко не определены. Работы вышеобозначенных исследователей, а также труды ученых, изучавших проблему готовности к инновационной деятельности специалистов других областей [Хомерики, 1994; Подласый, 2012; Иванова, Дубенкова, 2014; Гуреев, Гришин, 2017 и др.] подтверждают необходимость восполнить данный пробел. В связи с этим целью данного исследования является выявление особенностей современной практики формирования готовности к инновационной деятельности будущих специалистов сферы государственного управления и определение критериального аппарата для создания модели формирования готовности будущих специалистов сферы государственного управления.

\section{Определения основных понятий}

Опираясь на исследования ученых, изучавших готовность к инновационной деятельности, в частности профессиональную готовность к инновационной деятельности будущих специалистов сферы государственного управления [Хомерики, 1994; Подласый, 2012; Никитина 2013; Долгова, 2013; Коновалова, 2013; Кузьменко, 2014; Иванова, Дубенкова, 2014; Чепляев, 2016; Атнашев, 2017; Гуреев, Гришин, 2017] мы сформулировали определения понятий «инновационная деятельность будущего специалиста в сфере государственного управления» и «профессиональная готовность будущего специалиста в сфере государственного управления к инновационной деятельности».

Инноващионная деятельность будущего специалиста в сфере государственного управления - это вид профессиональной деятельности, предполагающий наличие у специалистов высокого уровня профессиональной подготовки, интеллектуальной наполненности, креативного мышления, способности к использованию в своей работе принципиально новых подходов, методов иинструментов управления.

Готовность к инновационной деятельности будущих спещииалистов сферы государственного управления предполагает понимание инноваций, способов и особенностей их применения, наличие соответствующих личностных особенностей, профессиональных навыков, положительного отношения к инновациям и субъектам, вовлеченным в инновационные формы взаимодействия, а также умение быстро и профессионально выполнять задачи в нестандартных условиях, способность применять креативные, творческие, коммуникативные способности и навыки. Это не сформированные модели и формы поведения, а готовность и умение находить эффективные способы решения нестандартных задач, используя инновационный потенциал (совокупность различных ресурсов, необходимых для осуществления инновационной деятельности).

В целом можно сказать, что профессиональная готовность будущего специалиста в сфере государственного управления к инновационной деятельности - это состояние личности, выражающееся в способности выполнения функций государства, принятия социально-значимых решений, характеризующееся целостной структурой, включающей мотивационно-ценностный, интеллектуально-информационный, процессуальнодеятельностный, рефлексивно-аналитический компоненты, и предполагающее умение использовать принципиально новые подходы, методы и инструменты управления.

\section{Анализ нормативной базы}

Сегодня основными документами, регламентирующими подготовку государственных гражданских служащих, являются:

- Государственный образовательный стандарт высшего образования по направлению подготовки 38.03.04 «Государственное и муниципальное управление» (уровень бакалавриата) [Государственный образовательный..., 2020а]; 
- Государственный образовательный стандарт высшего образования по направлению подготовки 38.04.04 «Государственное и муниципальное управление» (уровень магистратуры) [Государственный образовательный..., 2020б];

- «Справочник квалификационных требований к специальностям, направлениям подготовки, знаниям, умениям, которые необходимы для замещения должностей государственной гражданской службы с учетом области и вида профессиональной служебной деятельности государственных гражданских служащих» [Справочник квалификационных..., 2017];

- образовательные программы по направлению подготовки 38.03 .04 «Государственное и муниципальное управление» (уровень бакалавриата) и по направлению подготовки 38.04.04 «Государственное и муниципальное управление» (уровень магистратуры) [Основная образовательная..., 2020].

Мы предполагали, что квалификационные требования, представленные в «Справочнике», должны иметь полное соответствие с федеральными государственными образовательными стандартами высшего образования и образовательными программами по направлению подготовки 38.03.04 «Государственное и муниципальное управление» (уровень бакалавриата). Содержательный анализ «Справочника» показал, что требования к готовности будущих служащих к инновационной деятельности в процессе их профессиональной деятельности в документе практически отсутствуют, хотя реальная практика работы в аппарате государственной службы актуализирует данный аспект подготовки будущих специалистов. Только лишь одна позиция в блоке базовых требований- «умение управлять изменениями» - указывает на необходимость такой подготовки.

На основе проведенного анализа ФГОС ВО по направлению подготовки 38.03.04 «Государственное и муниципальное управление» (уровень бакалавриата) от 13.08.2020 № 1016 можем отметить, что необходимость формирования готовности будущих специалистов к инновационной деятельности в процессе профессиональной подготовки в этом документе, как и в «Справочнике», отражена недостаточно.

Анализ основной образовательной программы высшего образования (ООП ВО) направления подготовки 38.03.04 «Государственное и муниципальное управление», профиль «Государственное управление таможенными процессами», квалификация «Бакалавр» ГОУ ВО «Луганский государственный университет имени Владимира Даля», показал, что в соответствии с каждым видом профессиональной деятельности в программе сформулированы профессиональные задачи, большинство из которых коррелируют с инновационной деятельностью в процессе выполнения служащими профессиональных функций и требуют осведомленности будущего госслужащего в проблематике использования различного рода инноваций в профессии.

В целом заметим, что данные документы хоть и коррелируются, но в тоже время имеют существенные расхождения. Например, в «Справочнике» размещены 144 требования к знаниям, умениям и навыкам будущих госслужащих, которые объединены в пять групп (компетенций). Стандарты включают 18 компетенций, из них универсальных компетенций - 11, общепрофессиональных - 7. Отметим, что общепрофессиональные компетенции, перечисленные в стандартах, не соотносятся с описанными в Справочнике. В тоже время некоторые функциональные обязанности не отражены в ФГОС ВО. В свою очередь основная образовательная программа по направлению «Государственное управление таможенными процессами» (ООП ГУТП) предполагает формирование девяти общекультурных (ОК), шести общепрофессиональных (ОПК) и двадцати семи профессиональных (ПК) компетенций. Сопоставив компетенции ООП ГУТП с ФГОС ВО и «Справочником», мы пришли к заключению, что все три документа имеют расхождения в различных позициях, хотя для эффективной подготовки специалистов в сфере государственного управления необходимо полное соответствие изученных нормативных документов. 


\section{Критерии, показатели, уровни готовности к инновационной деятельности будущих специалистов сферы государственного управления}

Опираясь на результаты исследования готовности будущих специалистов сферы государственного управления к инновационной деятельности [Провоторова, 2020a; 2020б] и учитывая специфику инновационной деятельности [Провоторова, 2021], мы определили, что формирование изучаемой готовности как системного многоуровневого явления со сложной динамической структурой осуществляется в процессе профессионального образования и включает мотивационно-ценностный, интеллектуально-информационный, процессуально-деятельностный и рефлексивно-аналитический компоненты.

В нашем исследовании мы рассматриваем составляющие основных компонентов структуры готовности к инновационной деятельности будущих специалистов сферы государственного управления как критерии ее сформировонности.

Мотивационно-ценностный критерий содержательно наполняет система мотивов (материальные и духовные потребности, склонности, стремления, побуждения общественного и собственно-социального характера); ценностных ориентаций (профессионализм, карьера, положение в обществе, благополучие, социальный престиж и др.) и установок будущего госслужащего (готовность к профессиональному росту, ориентация на формирование своего собственного профессионального стиля, достижение стойкой профессиональной успешности и др.). Основными показателями мотивационно-ценностного критерия нами определены: значимость для будущих госслужащих мотивов профессиональной деятельности; мотивация будущих специалистов в сфере государственного управления к успеху.

Интеллектуально-информащионный критерий отражает степень овладения профессиональными знаниями, умениями и навыками; уровень готовности овладения навыками инновационной деятельности в профессии, а также технологиями принятия рациональных решений; умение адаптироваться к различным изменениям, прогнозировать ход развития той или иной рабочей ситуации, используя инновационные подходы, методы и приемы. Основными показателями интеллектуально-информационного критерия нами определены: средний балл успеваемости обучающихся; усвоение ими основных понятий профессиональной деятельности в сфере государственной службы; осведомленность студентов в проблематике инновационных процессов в аппарате государственной службы.

Процессуально-деятельностный критерий определяется спецификой видов профессиональной деятельности будущего госуправленца и необходимостью выполнения работы в государственном управлении. Результаты исследования показали, что в основу федерального государственного стандарта высшего образования - бакалавриат по направлению подготовки 38.03.04 «Государственное и муниципальное управление» положен деятельностный подход, который обуславливает формирование системы профессиональных умений, способность решать стандартные и специфические профессиональные задачи. Будущий специалист должен быть способен к планированию и программированию своей профессиональной деятельности, обладать системой умений и навыков, а также неким практическим опытом, который может быть приобретен и в процессе прохождения практик студентами.

Учитывая значимость сформированности системы умений в профессии и необходимость формирования готовности будущих специалистов в системе государственной службы к инновационной деятельности, основными показателями процессуальнодеятельностного критерия нами определены: осмысленность профессиональных действий, наличие креативного мышления у обучающегося.

Рефлексивно-аналитический критерий готовности будущих специалистов к инновационной деятельности определяет уровень профессиональной ответственности, крити- 
ческого мышления студентов, профессиональной этики и морали, способности к самосовершенствованию, профессиональному росту и отражает соответствие индивидуальных качеств студента существующим требованиям к специалисту аппарата госслужбы; осознание и глубокое осмысления своего реагирования в случае возникновения нестандартных рабочих ситуаций; анализ личностного смысла в собственных профессиональных действиях; умение конструктивно разрешать внутриличностные и межличностные противоречия и конфликты.

Рассматривая рефлексию как направленность сознания будущего специалиста в сфере государственной службы на глубокую осознанность профессиональной деятельности, самодетерминацию, самоанализ, самооценку и основу развития профессиональной самотождественности и ответственности за результаты своей профессиональной деятельности, показателями рефлексивно-аналитического критерия мы определили самоанализ сформированности профессиональной готовности будущего специалиста к инновационной деятельности, самооценку реализации необходимости в самосовершенствовании.

На основе выделенных критериев и показателей охарактеризованы три уровня готовности будущего специалиста сфере государственного управления к инновационной деятельности - низкий, средний и высокий.

Низкий уровень готовности характеризуется низким уровнем значимости для будущих специалистов мотивов профессиональной деятельности; их заинтересованности в профессиональных достижениях, отсутствием интереса к выполнению профессиональных действий, направленных на решение профессиональных задач; отсутствием осмысленности профессиональных действий; слабой выраженностью рефлексивно-аналитических качеств; отсутствием способности формировать самооценку реализации необходимости в самосовершенствовании и понимании необходимости инновационной деятельности в процессе осуществления государственного управления.

Средний уровень готовности будущего специалиста сфере государственного управления к инновационной деятельности характеризуется заинтересованностью в профессиональных достижениях, проявлением интереса к выполнению профессиональных действий, направленных на решение профессиональных задач; сформированной мотивацией к достижению успеха; достаточной степенью ориентации в проблематике инновационных процессов в аппарате государственного управления; сложившейся системой саморазвития и самоанализа; осознанной необходимостью осуществления инновационной деятельности в процессе выполнения функций в системе государственного управления.

Высокий уровень готовности будущего специалиста сфере государственного управления к инновационной деятельности характеризуется неоспоримой приоритетностью мотивов профессиональной деятельности; высокой степенью заинтересованности в профессиональных достижениях, проявлением личного интереса к выполнению профессиональных действий, направленных на решение профессиональных задач; высокой мотивацией к достижению успеха; полной осознанностью владения профессиональными умениями и действиями; высоким уровнем эрудиции; высоким стремлением к саморазвитию; способностью к глубокому анализу профессиональных ситуаций; полным пониманием процесса профессиональной подготовки.

\section{Выводы}

В результате исследования были разработаны критерии (мотивационноценностный, интеллектуально-информационный, процессуально-деятельностный, рефлексивно-аналитический), определены показатели (значимость для будущих госслужащих мотивов профессиональной деятельности; мотивация будущих специалистов в сфере государственного управления к успеху; средний балл успеваемости обучающихся; уровень усвоения основных понятий профессиональной деятельности в сфере государственной службы; осведомленность студентов в проблематике инновационных процессов в аппара- 
те государственной службы; способность к планированию и программированию своей профессиональной деятельности, наличие системы умений и навыков, наличие практического опыта; способность к самоанализу сформированности профессиональной готовности будущего специалиста к инновационной деятельности, самооценка реализации необходимости в самосовершенствовании), уровни (низкий, средний, высокий) профессиональной готовности к инновационной деятельности будущих специалистов сферы государственного управления.

Сделан вывод о том, что современные университеты не состоятельны в отношении удовлетворения социального запроса в специалистах сферы государственного управления, способных к осуществлению инновационной деятельности по следующим причинам:

- в нормативных документах, регламентирующих подготовку будущих специалистов сферы государственного управления (справочнике, стандартах, образовательных программах) практически отсутствуют необходимые компетенции, а в образовательных программах дисциплины, направленные на формирование готовности будущих специалистов к инновационной деятельности в профессии.

- сравнительный анализ содержания «Справочника», ФГОС ВО по направлению подготовки 38.03.04 «Государственное и муниципальное управление» (уровень бакалавриат) и ООП ГУТП направления подготовки 38.03 .04 «Государственное и муниципальное управление», профиль «Государственное управление таможенными процессами»,квалификация «Бакалавр» ГОУ ВО «Луганский государственный университет имени Владимира Даля», показал, что данные документы хоть и коррелируются, но в тоже время имеют существенные расхождения, что снижает эффективность подготовки специалистов сферы государственного управления в целом, а также уровень их готовности к инновационной деятельности.

- в программы существующих в учебном процессе практик не включены задачи, и соответственно, задания, направленные на ознакомление студентов с инновациями в системе государственного управления. По нашему мнению, это вызывает дополнительные затруднения в адаптационном процессе молодого специалиста к профессии, а также существенно снижает возможность использования специалистами в работе инноваций разного содержания и уровня.

Полученные результаты свидетельствуют о необходимости модернизации системы подготовки будущих специалистов сферы государственного управления. Разработанный нами критериальный аппарат является диагностическим инструментарием для анализа результатов педагогических экспериментов, которые определят уровень сформированности готовности будущих государственных служащих к инновационной деятельности на разных этапах. В дальнейших наших исследованиях будет разработана и внедрена в учебный процесс «Модель формирования готовности будущих специалистов сферы государственного управления», что существенно повысит эффективность их профессиональной подготовки.

\section{Список источников}

1. Государственный образовательный стандарт высшего образования - бакалавриат по направлению подготовки 38.03.04 Государственное и муниципальное управление (утвержден приказом министерства науки и высшего образования Российской Федерации от 13.08.2020 № 1016). 2020a. URL: https://www.alt.ranepa.ru/files/texts/process/fgos_bak_gmu2020.pdf (дата обращения 28.03.2021)

2. Государственный образовательный стандарт высшего образования - магистратура по направлению подготовки 38.04.04 Государственное и муниципальное управление (утвержден приказом министерства науки и высшего образования Российской Федерации от 13.08.2020 № 1000). 2020б. URL: https://www.alt.ranepa.ru/files/texts/process/fgos_bak_gmu2020.pdf(дата обращения 29.03. 2021) 
3. Основная образовательная программа высшего образования направления подготовки 38.03 .04 «Государственное и муниципальное управление»: профиль «Государственное управление таможенными процессами»: квалификация «бакалавр»: принято ученым советом ГОУ ВО ЛНР «Луганский государственный университет имени Владимира Даля»: утверждено приказом ректора ГОУ ВО ЛНР «Луганский государственный университет имени Владимира Даля». 2020. Луганск, 226 с.

4. Справочник квалификационных требований к специальностям, направлениям подготовки, знаниям и умениям, которые необходимы для замещения должностей государственной гражданской службы с учетом области и вида профессиональной служебной деятельности государственных гражданских служащих. 2017. URL: https://www.garant.ru/products/ipo/ prime/doc/71610924/\#review (дата обращения 05.06. 2021)

\section{Список литературы}

1. Атнашев T.M. 2017. Самоотверженные чиновники? Факторы высокой мотивации госслужащих. Вопросы государственного и муниципального управления, 3: 149-166.

2. Гуреев П.М., Гришин В.Н. 2017. Инновационный потенциал: проблемы, определения и оценки. Инновации, 4(222): 89-92.

3. Долгова В.И. 2013. Теоретические предпосылки готовности руководителей к инновационной деятельности. В кн.: Дилемма эпохи: ограниченные социальные ресурсы, правила и механизмы их воспроизводства и использования. Сб. труд. Международной виртуальной Интернет-конференции (Лондон, 30 января - 05 февраля 2013). Лондон, Великобритания: 15-17. URL: http://gisap.eu/ru/node/22479 (дата обращения: 23.11.2020)

4. Зеер Э.Ф., Конюхова Е.Т. 2010. Психологические факторы влияния установки педагогов на инновационную деятельность. Образование и наука. Известия УрО РАО, 4(72): 41-49.

5. Иванова Н.Л., Дубененкова Н.Л. 2014. Внедрение инноваций в сфере государственного управления: проблемы и факторы. Вопросы управления, 4(29): 33-44.

6. Карелина А.В. 2009. Проблемы подготовки кадров государственных служащих в условиях проведения административной реформы: региональный аспект. Социология власти, 2 : $178-184$.

7. Нерадовская Л.С. 2010. К вопросу определения сущности и содержания понятия «инновационная компетентность» учителя общеобразовательного учреждения. Вестник Татарского государственного гуманитарно-педагогического университета, 3(21): 228-231.

8. Никитина А.С. 2013. Факторы, определяющие специфику инновационной деятельности государственных гражданских служащих. Дискуссия, 4(34): 76-82.

9. Марченко И.П., Марченко А.И. 2010. Профессиональная подготовка муниципальных служащих: проблемы и пути решения. Вопросы государственного и муниципального управления, 2: $185-195$.

10. Мустафина Л.И. Богатырева М.Р. 2014. Совершенствование профессиональной подготовки государственных и муниципальных служащих. Интернет-журнал науковедение, 2 (21): 62. URL: https://naukovedenie.ru/PDF/46EVN214.pdf (дата обращения: 11.03.2021)

11. Перинский Ю.Е. 2017. Содержание и компоненты профессиональной готовности учителя технологий к применению инновационных методов обучения. Актуальные проблемы гуманитарных и естественных наук, 3-4: 115-119.

12. Подласый И.П. 2007. Педагогика. Книга 1. Общие основы. М., ВЛАДОС, 527 с.

13. Провоторова Н.В. 2020а. Особенности профессиональной готовности будущих специалистов сферы государственного управления к инновационной деятельности. Гуманитарные исследования Центральной России, 4(17): 54-62.

14. Провоторова Н.В. 2020б. Структурапрофессиональной готовности будущих специалистов сферы государственного управления. Педагогические исследования, 3: 20-26.

15. Провоторова Н.В. 2021. Особенности инновационной деятельности будущих специалистов сферы государственного управления. Известия Балтийской государственной академии рыбопромыслового флота: психолого-педагогические науки, 1(55): 41-45.

16. Хомерики О.Г., Поташник М.М., Лоренсов А.В. 1994. Развитие школы как инновационный процесс. М., Новая школа, 64 с. 
17. Чепляев В.Л. 2016. Личностно-профессиональная готовность государственных служащих. Управленческое консультирование, 12 (96): 55-62.

18. Чурсина А.С. 2014. Готовность к инновационной деятельности как элемент системы подготовки современных специалистов. Современная высшая школа: инновационный аспект, 4 : $37-40$.

19. Акімов О.О. 2014. Професійна діяльність державних службовців в умовах євроінтеграції України: питання формування психологічної готовності. Київ, Центр учбової літератури, $176 \mathrm{c}$.

20. Загороднюк С.О., Акімов О.О. 2013. Компетенції державного службовця як основа психологічної готовності до професійної діяльності у євроінтеграційних умовах. В кн.: Ефективність державного управління. Збірник наукових праць. Вип.36. Під заг. ред. В.С. Загорського, А.В. Ліпенцева. Львів, ЛРІДУ НАДУ: 277-286.

21. Коновалова М. Інноваційність у державній службі як чинник розвитку національної інноваційної системи України. Вісник Національної академії державного управління, 96-103. URL: http://visnyk.academy.gov.ua/wp-content/uploads/2013/11/2012-4-14.pdf (дата обращения 19.11.2020)

22. Кузьменко Ю.О. 2014. Умови формування готовності державних службовців до аналітичної діяльності в системі освіти. Державне будівництво, 1. URL: http://nbuv. gov.ua/UJRN/DeBu_2014_1_26. (дата звернення: 02.02.2020)

23. Мельман В.О. 2017. Психологічні аспекти професійної діяльності державних службовців та посадових осіб місцевого самоврядування. В кн.: Теорія та практика державного управління. Збірник наукових праць. Вип. 4(59). Харків,ХарРІ НАДУ Магістр: 166-170. URL: http://nbuv.gov.ua/UJRN/Tpdu_2017_4_25 (дата звернення: 25.06.2021)

24. Ткачова Н.О. 2012. Формування готовності майбутніх учителів до впровадження інноваційних педагогічних технологій у практику роботи загальноосвітньої школи. В кн. Теорія та методика навчання та виховання. Збірник наукових праць. Вип. 32. Під заг. ред. О.М. Іонової. Харків, Харківський національний педагогічний університету імені Г.С. Сковороди: 174-181. URL: http://nbuv.gov.ua/j-pdf/znpkhnpu_ttmniv_2012_32_22.pdf (дата звернення: 19.06.2021)

\section{References}

1. Atnashev T.M. 2017. Self-sacrificing bureaucrats? High motivation factors of civil servants in russia. Public administration issues, 3: 149-166 (in Russian).

2. Gureev P.M., Grishin V.N. 2017. Innovatsionnyy potentsial: problemy, opredeleniya i otsenki [Innovation Potential: Problems, Definitions and Assessments]. Innovations, 4(222): 89-92.

3. Dolgova V.I. 2013. Teoreticheskie predposylki gotovnosti rukovoditelej k innovacionnoj dejatel'nosti [Theoretical prerequisites for managers ' readiness for innovation activity]. Dilemma jepohi: ogranichennye social'nye resursy, pravila i mehanizmy ih vosproizvodstva $\mathrm{i}$ ispol'zovanija: 15-17. Available at:: http://gisap.eu/ru/node/22479 (accessed: 23.11.2020)

4. Zeer E.F., Konyukhova E.T. 2010. Psikhologicheskie faktory vliyaniya ustanovki pedagogov na innovatsionnuyu deyatel'nost' [Psychological factors of the influence of the attitude of teachers on innovative activities]. Obrazovanie i nauka. Izvestiya UrO RAO, 4(72): 41-49.

5. Ivanova N.L., Dubenenkova N.L. 2014. Vnedrenie innovatsiy v sfere gosudarstvennogo upravleniya: problemy i faktory [Implementation of innovations in the field of public administration: problems and factors]. Management issues, 4(29): 33-44.

6. Karelina A.V. 2009. Problemy podgotovki kadrov gosudarstvennyh sluzhashhih v uslovijah provedenija administrativnoj reformy: regional'nyj aspekt [Problems of training civil servants in the context of administrative reform: a regional aspect]. Sociologija vlasti, 2: 178-184.

7. Neradovskaya L.S. 2010. K voprosu opredeleniya sushchnosti i soderzhaniya ponyatiya «innovatsionnaya kompetentnost'» uchitelya obshcheobrazovatel'nogo uchrezhdeniya [On the question of defining the essence and content of the concept of "innovative competence" of a teacher of a general education institution]. TSHPU Bulletin, 3(21): 228-231.

8. Nikitina A.S. 2013. Faktory, opredelyayushchie spetsifiku innovatsionnoy deyatel'nosti gosudarstvennykh grazhdanskikh sluzhashchikh [Factors determining the specifics of innovative activities of public civil servants]. Discussion, 4(34): 76-82. 
9. Marchenko I.P., Marchenko A.I. 2010. Professional'naja podgotovka municipal'nyh sluzhashhih: problemy i puti reshenija [Professional training of municipal employees: problems and solutions]. Voprosy gosudarstvennogo i municipal'nogo upravlenija, 2: 185-195.

10. Mustafina L.I. Bogatyreva M.R. 2014. Improving the training of state and municipal employees. Internet-zhurnal naukovedenie, 2 (21): p. 62 (in Russian). Available at: https://naukovedenie.ru/PDF/46 EVN214.pdf (Date of request: 11.03.2021)

11. Perinskiy Yu.E. 2017. Soderzhanie i komponenty professional'noy gotovnosti uchitelya tekhnologiy k primeneniyu innovatsionnykh metodov obucheniya [The content and components of the professional readiness of a technology teacher for the use of innovative teaching methods]. Aktual'nye problemy gumanitarnykh i estestvennykh nauk, 3-4: 115-119.

12. Podlasyy I.P. 2007. Pedagogika [Pedagogy]. Book 1. Obshchie osnovy [General basics]. M., Publ.VLADOS, $527 \mathrm{p}$.

13. Provotorova N.V. 2020a. Osobennosti professional'noy gotovnosti budushchikh spetsialistov sfery gosudarstvennogo upravleniya $\mathrm{k}$ innovatsionnoy deyatel'nosti [Features of the professional readiness of future specialists in the field of public administration for innovative activities]. Humanities Researches of the Central Russia, 4(17): 54-62.

14. Provotorova N.V. 2020b. Struktura professional'noy gotovnosti budushchikh spetsialistov sfery gosudarstvennogo upravleniya [The structure of the professional readiness of future specialists in the field of public administration]. Pedagogical research, 3: 20-26.

15. Provotorova N.V. 2021. Osobennosti innovatsionnoy deyatel'nosti budushchikh spetsialistov sfery gosudarstvennogo upravleniya [Features of innovative activities of future specialists in the field of public administration]. Tidings of Baltic State Fishing Fleet Academy: psychological and pedagogical sciences, 1(55): 41-45.

16. Khomeriki O.G., Potashnik M.M., Lorensov A.V. 1994. Razvitie shkoly kak innovatsionnyy protsess [School development as an innovative process]. M., Publ. Novaya shkola. 64 p.

17. Chepljaev V.L. 2016. Personal and professional readiness of public servants. Upravlencheskoe konsul'tirovanie, 12 (96): 55-62 (in Russian).

18. Chursina A.S. 2014. Readiness for innovative activity as an element of training a modern specialist. Sovremennaja vysshaja shkola: innovacionnyj aspekt, 4: 37-40 (in Russian).

19. Akimov O.O. 2014. Profesiina diyal'nist' derzhavnikh sluzhbovtsiv v umovakh evrointegratsiï Ukraïni: pitannya formuvannya psikhologichnoï gotovnosti [Professional activity of civil servants in the conditions of European integration of Ukraine: questions of formation of psychological readiness]. Kiïv, Publ. Tsentr uchbovoï literaturi, 176 p. (in Ukrainian)

20. Zagorodnyuk S.O., Akimov O.O. 2013. Kompetentsiï derzhavnogo sluzhbovtsya yak osnova psikhologichnoï gotovnosti do profesiinoï diyal'nosti u evrointegratsiinikh umovakh [Competences of a civil servant as a basis of psychological readiness for professional activity in European integration conditions]. In: Efektivnist' derzhavnogo upravlinnya [The effectiveness of public administration]. Zbirnik naukovikh prats'. Iss. 36. Eds. V.S, Zagors'kogo, A.V. Lipentsev. L'viv, LRIDU NADU: 277286. (in Ukrainian)

21. Konovalova M. 2012. Innovatsiinist' u derzhavnii sluzhbi yak chinnik rozvitku natsional'noï innovatsiinoï sistemi Ukraïni [Innovation in the civil service as a factor in the development of the national innovation system of Ukraine]. Available at: http://visnyk.academy.gov.ua/wpcontent/uploads/2013/11/2012-4-14.pdf (accessed:19.11.2020) (in Ukrainian)

22. Kuz'menko YU.O. 2014. Umovi formuvannya gotovnosti derzhavnikh sluzhbovtsiv do analitichnoï diyal'nosti $\mathrm{v}$ sistemi osviti [Conditions for the formation of readiness of civil servants for analytical activities in the education system]. State formation, 1. Available at: http://nbuv.gov.ua/UJRN/DeBu_2014_1_26. (accessed:02.02.2020) (in Ukrainian)

23. Mel'man V.O. 2017. Psikhologichni aspekti profesiinoï diyal'nosti derzhavnikh slu-zhbovtsiv ta posadovikh osib mistsevogo samovryaduvannya [Psychological aspects of professional activity of civil servants and local government officials]. In: Teoriya ta praktika derzhavnogo up-ravlinnya [Theory and practice of public administration]. Zbirnik naukovikh prats'.Iss.4(59). Khar-kiv, Publ. KharPI NADU Magistr: 166-170. Available at: http://nbuv.gov.ua/UJRN/Tpdu_2017_4_25. (accessed:25.06.2021)(in Ukrainian)

24. Tkachova N.O. 2012. Formuvannya gotovnosti maibutnikh uchiteliv do vprovadzhennya innovatsiinikh pedagogichnikh tekhnologii u praktiku roboti zagal'noosvitn'oï shkoli [Formation of readiness of future teachers for introduction of innovative pedagogical technologies in practice of work of 
comprehensive school]. In: Teoriya ta metodika navchannya ta vikhovannya [Theory and methods of teaching and education]. Zbirnik naukovikh prats'. Iss. 32. Ed. O.M. Ionova. Kharkiv, Publ. Kharkivs'kii natsional'nii pedagogichnii universitetu imeni G.S. Skovorodi: 174-181. Available at: http://nbuv.gov.ua/j-pdf/znpkhnpu_ttmniv_2012_32_22.pdf (accessed:19.06.2021) (in Ukrainian).

Конфликт интересов: о потенциальном конфликте интересов не сообщалось.

Conflict of interest: no potential conflict of interest related to this article was reported.

\section{ИНФОРМАЦИЯ ОБ АВТОРЕ}

Провоторова Наталия Викторовна, кандидат психологических наук, доцент, доцент кафедры психологии Луганского государственного педагогического университета, г. Луганск, ЛНР

\section{INFORMATION ABOUT THE AUTHOR}

Natalia V. Provotorova, Candidate of Sciences in Psychology, Associate Professor, Associate Professor of the Department of Psychology, Lugansk State Pedagogical University, Lugansk, LPR 